\title{
NOTE
}

\section{Cetacean strandings in Italy: an unusual mortality event along the Tyrrhenian Sea coast in 2013}

\author{
Cristina Casalone ${ }^{1, *}$, Sandro Mazzariol ${ }^{2}$, Alessandra Pautasso ${ }^{1}$, Giovanni Di Guardo ${ }^{3}$, \\ Fabio Di Nocera ${ }^{4}$, Giuseppe Lucifora ${ }^{4}$, Ciriaco Ligios ${ }^{5}$, Alessia Franco ${ }^{6}$, Gianluca Fichi ${ }^{6}$, \\ Cristiano Cocumelli ${ }^{6}$, Antonella Cersini ${ }^{6}$, Annalisa Guercio ${ }^{7}$, Roberto Puleio ${ }^{7}$, \\ Maria Goria ${ }^{1}$, Michela Podestà ${ }^{8}$, Letizia Marsili ${ }^{9}$, Gianni Pavan ${ }^{10}$, Antonio Pintore ${ }^{5}$, \\ Esterina De Carlo ${ }^{4}$, Claudia Eleni ${ }^{6}$, Santo Caracappa ${ }^{7}$ \\ ${ }^{1}$ IZS Piemonte Liguria Valle d'Aosta, Via Bologna, 148,10154 Torino, Italy \\ ${ }^{2}$ Department of Comparative Biomedicine and Food Science, University of Padua, Viale dell'Università 16, Agripolis, \\ 35020 Legnaro (PD), Italy \\ ${ }^{3}$ Faculty of Veterinary Medicine, University of Teramo, Piazza Aldo Moro, 45,64100 Teramo, Italy \\ ${ }^{4}$ IZS Mezzogiorno, Via delle Calabrie 27,84132 Salerno, Italy \\ ${ }^{5}$ IZS Sardegna, Duca degli Abruzzi 8,07100 Sassari, Italy \\ ${ }^{6}$ IZS Lazio Toscana, Via Appia Nuova, 1411,00178 Rome, Italy \\ ${ }^{7}$ IZS Sicilia, Via G. Marinuzzi, 9,90129 Palermo, Italy \\ ${ }^{8}$ Vertebrate Zoology Department, Museum of Natural History of Milan, C.so Venezia 55, 20121 Milano, Italy \\ ${ }^{9}$ Department of Earth, Physical and Environmental Sciences, University of Siena, Via P.A. Mattioli 4, 53100 Siena, Italy \\ ${ }^{10}$ CIBRA, Centro Interdisciplinare di Bioacustica e Ricerche Ambientali, Dept. of Earth and Environment Sciences, \\ Università di Pavia, Via Taramelli 24, 27100 Pavia, Italy
}

\begin{abstract}
An unusual mortality event involving cetaceans, mainly striped dolphins Stenella coeruleoalba (Meyen, 1833), occurred along the Tyrrhenian Sea coast of Italy during the first 3 mo of 2013. Based on post-mortem analyses carried out according to body condition on 66 dolphins (54\% of stranded animals), several hypotheses to explain the causes of this mortality event were proposed. Although no definitive conclusions can be drawn, dolphin morbillivirus was deemed the most likely cause, although other infectious agents (including Photobacterium damselae damselae and herpesvirus) or environmental factors may also have contributed to this recent mortality event.
\end{abstract}

KEY WORDS: Cetacean · Unusual mortality event · Dolphin · Morbillivirus · Marine mammal · Stranding

Resale or republication not permitted without written consent of the publisher

\section{INTRODUCTION}

Cetacean unusual mortality events (UMEs) refer to a marked rise in the number of strandings as compared with historical records for the same location and period (WGMMUME 2006). In the Mediterranean Sea, 3 different dolphin morbillivirus (DMV) dieoffs have occurred in the past $25 \mathrm{yr}$, each involving 100s - if not 1000s - of striped dolphins Stenella coeruleoalba (Meyen, 1833). The first was particularly dramatic and occurred between 1990 and 1992 (Domingo et al. 1992, Van Bressem et al. 2001) fol- lowed by a second one, also involving pilot whales Globicephala melas (Traill, 1809), between 2006 and 2008 (Fernández et al. 2008, Raga et al. 2008, Keck et al. 2010). A recent epidemic struck the coast of Spain (Soto et al. 2011) in 2011, before moving eastward and reaching Italian waters (Soto et al. 2011, Mazzariol et al. 2012, Rubio-Guerri et al. 2013a,b).

More recently, an exceptional number of cetacean strandings, 10 - to 12 -fold the $25 \mathrm{yr}$ average recorded for the same time period (Fig. 1), along the Tyrrhenian coast of Italy between January and March 2013 prompted diagnostic post-mortem investigation. 


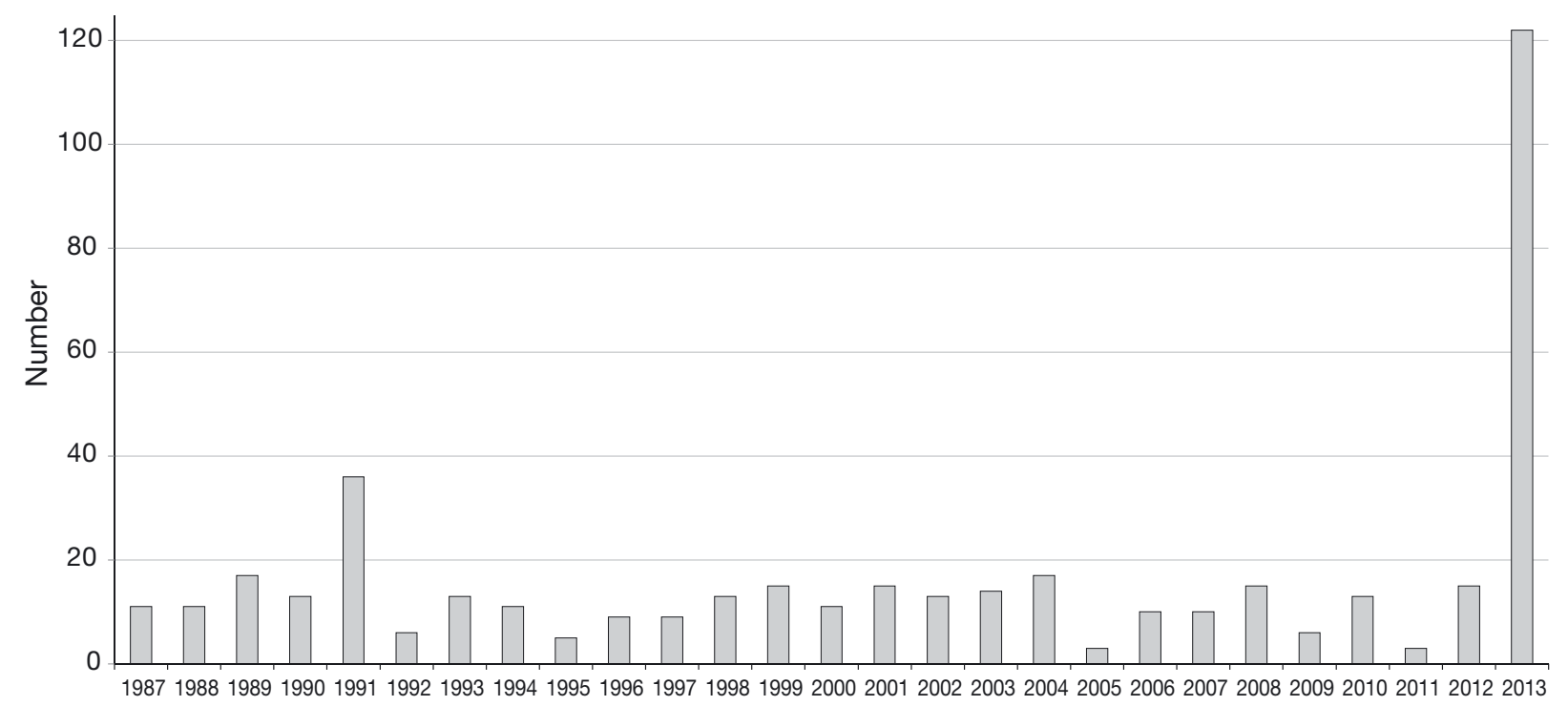

Fig. 1. Cetacean strandings recorded along the Tyrrhenian Sea coast of Italy (January to March quarter, 1987 to 2013)

\section{METHODS AND RESULTS}

A total of 122 stranded cetaceans were reported by the National Database on Cetacean Strandings (http:// mammiferimarini.unipv.it/index_en.php), including 96 striped dolphins Stenella coeruleoalba (Meyen, 1833), 7 bottlenose dolphins Tursiops truncatus (Montagu, 1821), 1 fin whale Balaenoptera physalus (Linnaeus, 1758), 1 pilot whale Globicephala melas (Traill, 1809) and 3 Risso's dolphins Grampus griseus (G. Cuvier, 1812). The species could not be determined in other 14 individuals (Fig. 2).

Age was estimated from total body length (TBL) in 80 striped dolphins (42 other specimens were directly disposed of by local health authorities due to poor preservation status), since direct techniques (e.g. counting growth layers in teeth and pectoral fin $\mathrm{X}$-rays) were impractical because of the high number of stranded animals. Two standard approaches (Di Meglio et al. 1996, Marsili et al. 2004) for Mediterranean striped dolphins determined that 77 animals $(96 \%)$ were younger than 20 yr of age, with a TBL shorter than $202 \mathrm{~cm}$.

Post-mortem investigations of 66 specimens (54\% of the stranded animals) were performed by various laboratories that used a standard sampling protocol according to the body conservation code (see Table 1) (Geraci \& Loundsbury 2005). Tissues (brain, lung, heart, kidney, liver, lymph node, spleen and skin) were sampled, frozen at $-80^{\circ} \mathrm{C}$ for microbiological and biomolecular investigations to identify the main cetacean pathogens (DMV, Brucella spp., Toxoplasma gondii, Photobacterium damselae subsp. damselae, herpesvirus) and preserved in $10 \%$ neutral-buffered formalin for histopathological and immunohistochemical (IHC) analyses.

Diagnostic investigations were performed whenever possible, according to the preservation conditions of the stranded animals. Logistic difficulties

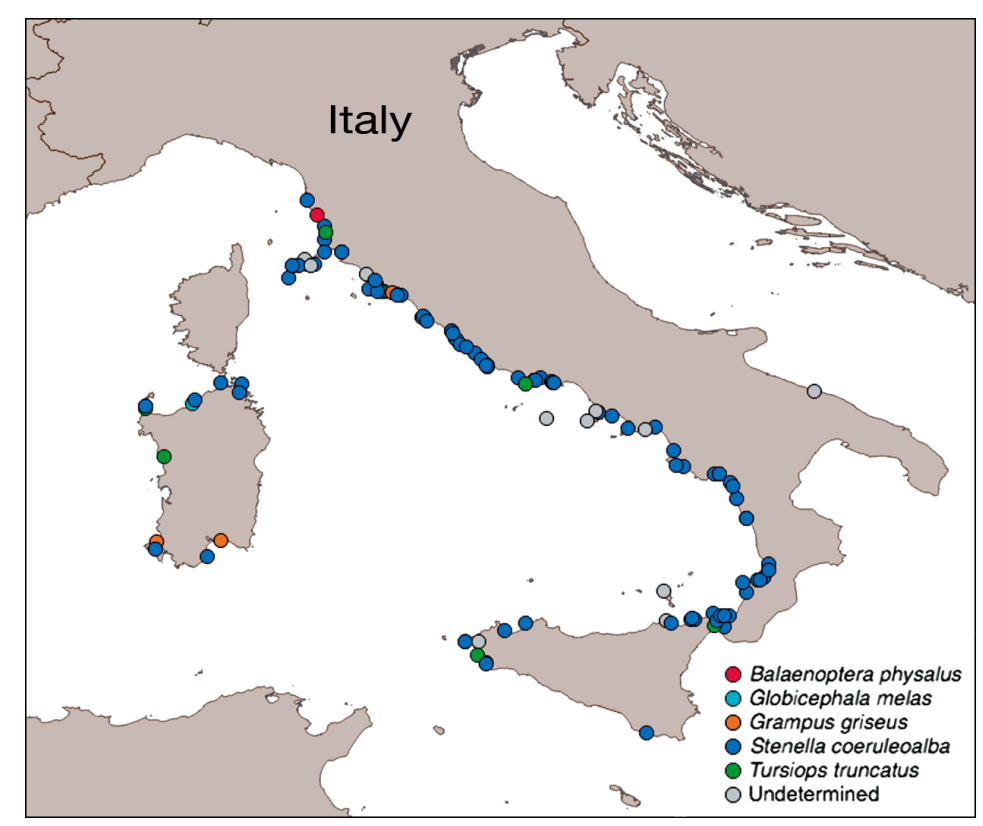

Fig. 2. Geographical distribution of recent cetacean strandings along the Italian coastline (1 January to 30 March 2013) 
Table 1. Body condition score of 63 stranded cetaceans according to Geraci \& Loundsbury (2005) (data not available for 3 animals) and diagnostic analysis. DMV: dolphin morbillivirus; T. gondii: Toxoplasma gondii; OC: organochlorine

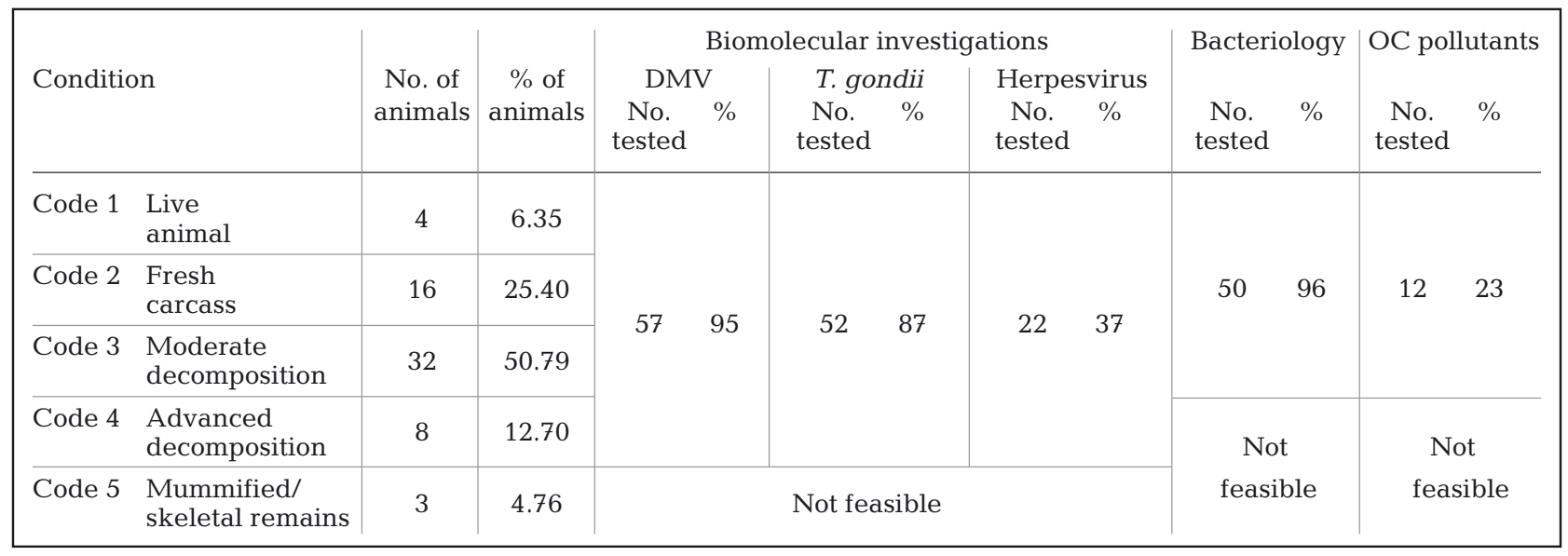

sometimes precluded thorough examination due to the large geographic area involved in this UME and the unexpectedly high number of cetaceans found stranded. Most carcasses (63\%) showed a moderateto-advanced degree of post-mortem autolysis, with empty stomachs and high loads of a range of parasites distributed throughout the body.

Biomolecular analyses for DMV (Raga et al. 2008, Di Guardo et al. 2010, Romano et al. 2011) and Toxoplasma gondii (Alba et al. 2013, Vitale et al. 2013) were performed in most animals triaged with codes from 1 to 4, while culture-based and molecular investigations for bacterial pathogens, including Brucella spp. (Alton et al. 1988, Carter 1992, OIE 2008) and Photobacterium damselae subsp. damselae (Holt et al. 1994, Osorio et al. 2000, Lozano-Leon et al. 2003, Labella et al. 2011, Woo \& Bruno 2011), were attempted in animals triaged with codes from 1 to 3 .

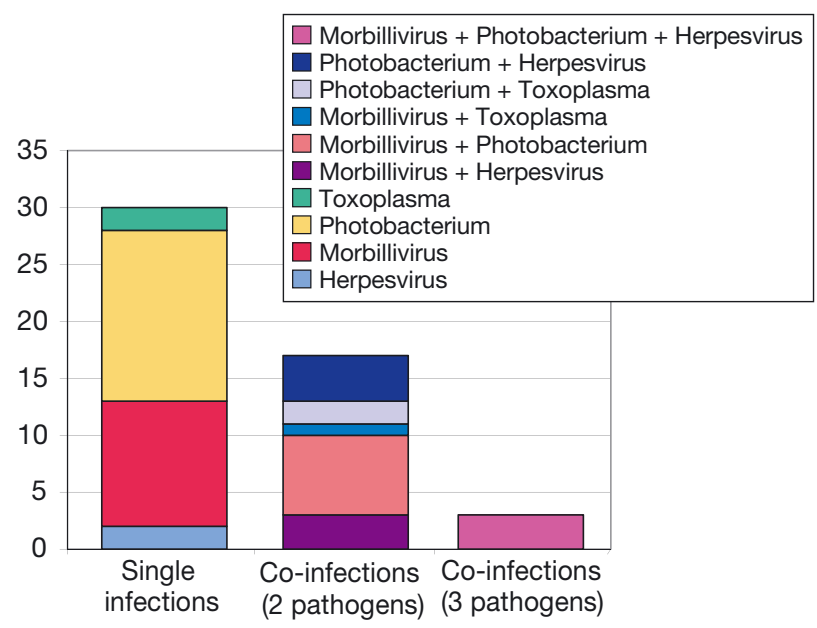

Fig. 3. Pathogens detected in necropsied cetaceans
Furthermore, single laboratories performed other related analyses, such as those against herpesvirus (VanDevanter et al. 1996, Rose 2005), which were mainly carried out on selected individuals with codes from 1 to 4 stranded along the coasts of Latium and Tuscany (22 animals, 37\%) and environmental organochlorine $(\mathrm{OC})$ pollutant determinations performed on a sample of 12 animals (23\%) with codes from 1 to 3 stranded along the coasts of Tuscany and Sicily (Table 1).

DMV was detected by means of reverse transcription-polymerase chain reaction (RT-PCR) in 24 out of 57 animals tested ( $42 \%$ ), mainly on samples from the brain or lungs. IHC analysis (Uchida et al. 1999) performed on animals that were RT-PCR-positive for DMV detected morbilliviral antigen in the brain of 1 dolphin. Other pathogens were frequently identified concurrently (Fig. 3).

Photobacterium damselae subsp. damselae was isolated from 31 out of 50 animals (62\%), mainly from the brain, liver, lungs and lymph nodes. Toxoplasma gondii was detected by biomolecular analysis in 5 out of 52 animals $(9.62 \%)$, mainly from the lungs and central nervous system (CNS), but without related pathological changes. Herpesvirus was detected in 12 out of 22 animals ( $54 \%$ ), mainly from the CNS, lungs and spleen. No characteristic histopathological changes generally attributed to herpesvirus infection were found. No evidence of Brucella spp. was detected in any of the tissues.

Histopathology revealed chronic inflammation in several organs (CNS, lung, kidney, liver, spleen) of almost all the animals. Furthermore, follicular depletion and hyalinosis in lymphoid tissues suggested impairment of the immune system, and eosinophilic 


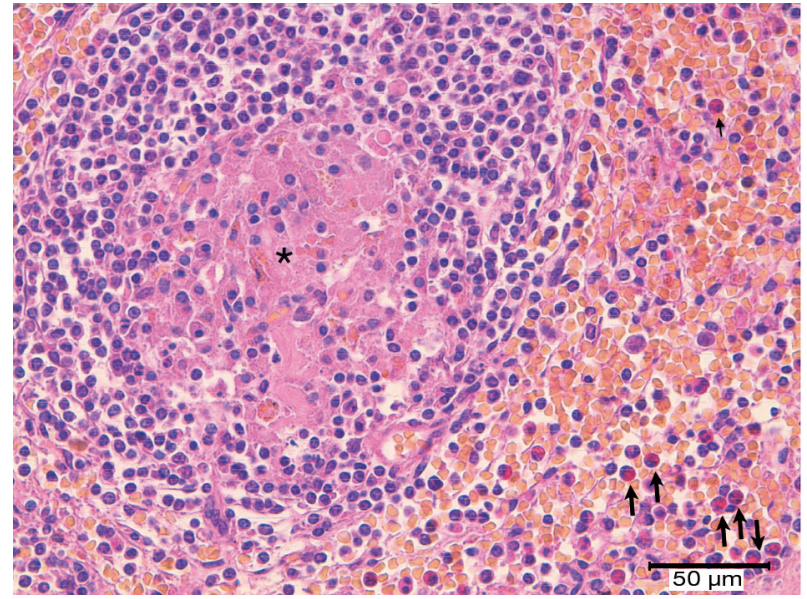

Fig. 4. Stenella coeruleoalba. A spleen probe from a dolphin morbillivirus-infected striped dolphin. Note the follicular hyalinosis (*) represented by abundant eosinophilic amorphous material filling the empty space due to severe lymphoid depletion. Furthermore, eosinophils can be noted scattered throughout the surrounding red pulp (arrows). Hematoxylin and eosin, scalebar $=50 \mu \mathrm{m}$

inflammatory infiltration was suggestive of a systemic reaction to parasites (Fig. 4). Finally, fibrinoid effusion and necrosis and/or hemolysis or hemorrhage in the spleen, lymph nodes, liver and kidneys were suggestive of acute septic shock and were often associated with the presence of pathogens in many animals.

Screening for OC pollutants, including hexachlorobenzene (HCB), dichlorodiphenyltrichloroethane (DDT) and polychlorobiphenyls (PCBs), was performed in blubber, muscle and liver of 12 animals according to Environmental Protection Agency (EPA) Method 8081/8082, with modifications (Marsili \&
Focardi 1997). Total PCBs were quantified as the sum of individual congeners (IUPAC Nos. 95, 101, 99,151, $144,135,149,118,146,153,141,138,178,187,183$, $128,174,177,156,171,202,172,180,199,170,196$, $201,195,194,206)$, while total DDTs were calculated as the sum of pp'DDT, op'DDT, pp'DDE, op'DDE, $\mathrm{pp}^{\prime} \mathrm{DDD}$ and op'DDD. Toxicological stress was evaluated using a theoretical model (Marsili et al. 2004) that estimates hazardous levels of OC pollutants at a canonical variable value $>0.47$ (Table 2 ) .

\section{DISCUSSION}

The microscopic findings, high parasite burdens and infections all point to immunocompromise of the cetaceans involved in this UME, which is particularly noteworthy because it involved young individuals belonging to a single species and occurred within a very short period of time and within a well-defined area. Furthermore, the immune system and its response may have been impaired by co-existing DMV infection and high tissue levels of OC pollutants in some of the stranded animals, making them more susceptible to secondary infections by other pathogens.

Morbillivirus is considered the most pathogenic viral agent for cetaceans. Endemic infections with milder lesions and lighter pathogen loads have been described in the western Mediterranean (RubioGuerri et al. 2013b); however, DMV displays a 'cyclic behavior', with seasonal outbreaks in this area. Indeed, the agent tends to 'reappear' as a population's anti-viral immune response decreases, leaving animals more susceptible to clinical disease.

Table 2. Levels of hexachlorobenzene (HCB), dichlorodiphenyltrichloroethane (DDT) and polychlorobiphenyls (PCBs) (ng $\mathrm{g}^{-1}$ dry wt) in the blubber of 12 cetaceans. Toxicological stress as evaluated according to the model proposed by Marsili et al. (2004). Bold entries denote animals with hazardous levels of organochlorines (canonical variable [CAN] value > 0.47). DMV: dolphin morbillivirus; CNS: central nervous system

\begin{tabular}{|rrrrll|}
\hline ID & HCB & \multicolumn{1}{c}{ DDTs } & \multicolumn{1}{c|}{ PCBs } & CAN value & Pathological findings \\
\hline 22 & 301.4 & 63493.0 & 85625.0 & 0.17 & Parasites \\
23 & 179.5 & 25512.4 & 59594.4 & -0.24 & Parasites \\
$\mathbf{3 1}$ & $\mathbf{8 4 7 . 1}$ & $\mathbf{4 4 5 5 8 2 . 0}$ & $\mathbf{4 7 1 0 1 3 . 0}$ & $\mathbf{5 . 5 2}$ & DMV (CNS, lungs); parasites \\
57 & 50.7 & 3162.8 & 10096.2 & -0.81 & Photobacterium damselae (multiple organs) \\
$\mathbf{5 8}$ & $\mathbf{2 3 4 . 2}$ & $\mathbf{2 2 5 5 5 8 . 6}$ & $\mathbf{2 1 5 6 9 4 . 5}$ & $\mathbf{2 . 1 2}$ & DMV (lungs) \\
$\mathbf{5 9}$ & $\mathbf{4 1 7 . 1}$ & $\mathbf{1 3 3 7 0 4 . 0}$ & $\mathbf{1 5 9 8 5 5 . 7}$ & $\mathbf{1 . 1 9}$ & DMV (heart); Photobacterium damselae (lungs) \\
60 & 1287.9 & 97955.9 & 92773.9 & 0.39 & Parasites \\
$\mathbf{6 2}$ & $\mathbf{2 3 2 . 2}$ & $\mathbf{2 3 3 7 1 7 . 7}$ & $\mathbf{3 1 8 4 5 8 . 6}$ & $\mathbf{3 . 1 4}$ & DMV (CNS, heart, lungs) \\
$\mathbf{6 3}$ & $\mathbf{4 7 8 . 2}$ & $\mathbf{1 6 3 0 4 3 . 3}$ & $\mathbf{1 7 8 4 3 1 . 9}$ & $\mathbf{1 . 4 9}$ & Photobacterium damselae (multiple organs) \\
$\mathbf{6 4}$ & $\mathbf{2 0 0 . 3}$ & $\mathbf{8 3 6 8 9 . 0}$ & $\mathbf{1 1 0 4 5 0 . 6}$ & $\mathbf{0 . 5 0}$ & DMV (CNS) \\
$\mathbf{6 5}$ & $\mathbf{3 4 9 . 7}$ & $\mathbf{9 6 5 3 9 . 1}$ & $\mathbf{1 4 0 5 8 1 . 9}$ & $\mathbf{0 . 8 4}$ & Photobacterium damselae (multiple organs) \\
66 & 473.7 & 11718.1 & 35953.3 & -0.53 & Photobacterium damselae (multiple organs) \\
\hline
\end{tabular}


Despite the lack of a range of characteristic morphologic changes in the tissues from the DMVinfected animals, biomolecular investigations yielded clear evidence for DMV infections in $42 \%$ of those tested, supporting the hypothesis that DMV played an important role in this mortality outbreak. Given the geographical range of the strandings and the preservation status of the carcasses, the animals likely belonged to cetacean groups living in the southern Tyrrhenian Sea. The only DMV outbreak - the largest one to datereported for this area occurred in 1990 to 1992, whereas the 2 DMV outbreaks in 2006 to 2008 and 2010 to 2011 occurred in the western and northern Mediterranean basins (Di Guardo et al. 1995, Van Bressem et al. 2001, Di Guardo \& Mazzariol 2013). Most of the animals in this UME were probably $<20$ yr of age, not previously exposed to DMV and, therefore, likely lacked adequate immunity; immunity to infection gradually tends to wane with the absence of recurrent infections in a population. Also, the level of anti-viral immunity in these animals or their relatives and conspecifics could have been impaired by other immunosuppressive agents, such as the high tissue levels of OC pollutants found in the stranded animals. Furthermore, because both DMV and OCs are known to impair host immune response, this could have led to secondary infections by other pathogens in the DMVinfected dolphins. Morbillivirus and herpesvirus infections have been reported to co-occur within the Mediterranean striped dolphin population, with co-infected animals frequently showing morbilliviral- but not herpesviral-related lesions (Bellière et al. 2010).

Usually considered an opportunistic pathogen, Photobacterium damselae subsp. damselae was identified in $62 \%$ of the stranded dolphins. Although some strains are known to be highly pathogenic for laboratory mammals under experimental conditions (Rivas et al. 2013), a clear association between this bacterium and mass mortality events or epidemic outbreaks in aquatic mammals has never been demonstrated. Little is known about the pathogenic significance of this microbial agent for free-ranging cetaceans. Equally critical is that few studies to date have investigated the entire viral genome of isolates recovered from morbillivirus-infected cetaceans. Future studies are therefore needed to characterize virus- and host-related factors in host-DMV interaction, as well as climate change-related factors contributing to the 'cyclic' occurrence of DMV epidemics in the Mediterranean.
No definitive conclusions on the causes of this cetacean UME can be drawn. Nonetheless, the effects possibly exerted by DMV infection on the immune system of the infected cetaceans may have contributed to this UME, in association with such other well-known immunosuppressive agents as OC contaminants. Other undetermined, unknown, or known environmental factors, such as reduced prey availability due to competition with human fishing activities, may have augmented the lethal effects of non-infectious or infectious agents such as Photobacterium damselae damselae or herpesvirus.

Acknowledgements. We thank the Italian Ministries of the Environment and of Health for having supported and partially funded this study. Particular thanks are due to Nicola Santini (Ministry of Health) and Paolo Galoppini (Ministry of the Environment) for their efforts in establishing the Italian Marine Mammals Stranding Network and the online Databank. A special note of thanks goes to the Italian Coast Guard for the daily monitoring of strandings. Furthermore, we thank Fabrizio Serena and Cecilia Mancusi (ARPA Toscana) for their assistance in collecting the carcasses along the Tuscan coastline. Finally, Bruno Cozzi and the staff of the Mediterranean Marine Mammal Tissue Bank are gratefully acknowledged for their assistance in collecting, preserving and distributing the samples.

\section{LITERATURE CITED}

Alba P, Terracciano G, Franco A, Lorenzetti S and others (2013) The presence of Brucella ceti ST26 in a striped dolphin (Stenella coeruleoalba) with meningoencephalitis from the Mediterranean Sea. Vet Microbiol 164: $158-163$

Alton GG, Jones LM, Angus RD, Verger JM (1988) Techniques for the brucellosis laboratory. INRA Publications, Paris

> Bellière EN, Esperón F, Arbelo M, Muñoz MJ, Fernández A, Sánchez-Vizcaíno JM (2010) Presence of herpesvirus in striped dolphins stranded during the cetacean morbillivirus epizootic along the Mediterranean Spanish coast in 2007. Arch Virol 155:1307-1311

Carter GR (1992) Diagnostic procedures in veterinary bacteriology and mycology, 5th edn. Academic Press, San Diego, CA

> Di Guardo G, Mazzariol S (2013) Dolphin morbillivirus: a lethal but valuable infection model. Emerg Microb Infect 2:e74

Di Guardo G, Agrimi U, Morelli L, Cardeti G, Terracciano G, Kennedy S (1995) Postmortem investigations on cetaceans found stranded on the coasts of Italy between 1990 and 1993. Vet Rec 136:439-442

- Di Guardo G, Proietto U, Di Francesco CE, Marsilio F and others (2010) Cerebral toxoplasmosis in striped dolphins (Stenella coeruleoalba) stranded along the Ligurian Sea coast of Italy. Vet Pathol 47:245-253

Di Méglio N, Romero-Alvarez R, Collet A (1996) Growth comparison in striped dolphins, Stenella coeruleoalba, from the Atlantic and Mediterranean coasts of France. Aquat Mamm 22:11-19 
Domingo M, Visa J, Pumarola M, Marco AJ, Ferrer L, Rabanal R, Kennedy S (1992) Pathologic and immunocytochemical studies of morbillivirus infection in striped dolphins (Stenella coeruleoalba). Vet Pathol 29:1-10

Fernández A, Esperón F, Herraéz P, de Los Monteros AE and others (2008) Morbillivirus and pilot whale deaths, Mediterranean Sea. Emerg Infect Dis 14:792-794

Geraci JR, Loundsbury VJ (2005) Marine mammals ashore: a field guide for strandings, 2nd edn. National Aquarium in Baltimore, Baltimore, MD, p 167-228

Holt JG, Krieg NR, Sneath PHA, Staley JT, Williams ST (1994) Bergey's manual of determinative bacteriology, 9th edn. Williams \& Wilkins, Baltimore, MD

Keck N, Kwiatek O, Dhermain F, Dupraz F and others (2010) Resurgence of morbillivirus infection in Mediterranean dolphins off the French coast. Vet Rec 166:654-655

Labella A, Berbel C, Manchado M, Castro D, Borrego JJ (2011) Photobacterium damselae subsp. damselae, an emerging pathogen affecting new cultured marine fish species in southern Spain. In: Aral F (ed) Recent advances in fish farms. InTech, Rijeka, p 135-152

Lozano-Leon A, Osorio CR, Nuñez S, Martinez-Urtaza J, Magariños B (2003) Occurrence of Photobacterium damselae subsp. damselae in bivalve molluscs from Northwest Spain. Bull Eur Assoc Fish Pathol 23:40-44

Marsili L, Focardi S (1997) Chlorinated hydrocarbon (HCB, DDTs and PCBs) levels in cetaceans stranded along the Italian coasts: an overview. Environ Monit Assess 45: 129-180

Marsili L, D'Agostino A, Bucalossi D, Malatesta T, Fossi MC (2004) Theoretical models to evaluate hazard due to organochlorine compounds (OCs) in Mediterranean striped dolphin (Stenella coeruleoalba). Chemosphere 56:791-801

> Mazzariol S, Marcer F, Mignone W, Serracca L, Goria M, Marsili L, Di Guardo G, Casalone C (2012) Dolphin morbillivirus and Toxoplasma gondii coinfection in a Mediterranean fin whale (Balaenoptera physalus). BMC Vet Res 8:20

OIE (World Organization for Animal Health) (2008) Manual of diagnostic tests and vaccines for terrestrial animals, 6th edn. OIE, Paris

> Osorio CR, Toranzo AE, Romalde JL, Barja JL (2000) Multiplex PCR assay for ureC and 16S rRNA genes clearly discriminates between both subspecies of Photobacterium damselae. Dis Aquat Org 40:177-183

Raga JA, Banyard A, Domingo M, Corteyn M and others (2008) Dolphin morbillivirus epizootic resurgence, Mediterranean Sea. Emerg Infect Dis 14:471-473

Editorial responsibility: Sven Klimpel, Frankfurt, Germany
Rivas AJ, Balado M, Lemos ML, Osorio CR (2013) Synergistic and additive effects of chromosomal and plasmidencoded hemolysins contribute to hemolysis and virulence in Photobacterium damselae subsp. damselae. Infect Immun 81:3287-3299

Romano A, Sant S, Grattarola C, Iulini B and others (2011) PCR-RFLP come strumento di diagnosi identificazione di morbillivirus. In: ISTISAN 11/C3, 4th National Workshop on Veterinary Virology, No. 2, 6th suppl, p 81 (abstract)

$>$ Rose TM (2005) CODEHOP-mediated PCR-A powerful technique for the identification and characterization of viral genomes. Virol J 2:20

> Rubio-Guerri C, Melero M, Rivera-Arroyo B, Bellière EN and others (2013a) Simultaneous diagnosis of cetacean morbillivirus infection in dolphins stranded in the Spanish Mediterranean Sea in 2011 using a novel universal probe library (UPL) RT-PCR assay. Vet Microbiol 165:109-114

Rubio-Guerri C, Melero M, Esperón F, Bellière EN and others (2013b) Unusual striped dolphin mass mortality episode related to cetacean morbillivirus in the Spanish Mediterranean Sea. BMC Vet Res 9:106

> Soto S, Alba A, Ganges L, Vidal E and others (2011) Postepizootic chronic dolphin morbillivirus infection in Mediterranean striped dolphins Stenella coeruleoalba. Dis Aquat Org 96:187-194

Uchida K, Muranaka M, Horii Y, Murakami N, Yamaguchi R, Tateyama S (1999) Non-purulent meningoencephalomyelitis of a Pacific striped dolphin (Lagenorhynchus obliquidens). The first evidence of morbillivirus infection in a dolphin at the Pacific Ocean around Japan. J Vet Med Sci 61:159-162

> Van Bressem M, Waerebeek KV, Jepson PD, Raga JA and others (2001) An insight into the epidemiology of dolphin morbillivirus worldwide. Vet Microbiol 81:287-304

> VanDevanter DR, Warrener P, Bennett L, Schultz ER, Coulter S, Garber RL, Rose TM (1996) Detection and analysis of diverse herpesviral species by consensus primer PCR. J Clin Microbiol 34:1666-1671

Vitale M, Galluzzo P, Currò V, Gozdzik K, Schillaci D, Di Marco Lo Presti V (2013) A high sensitive nested PCR for Toxoplasma gondii detection in animal and food samples. J Microb Biochem Technol 5:39-41

Woo PTK, Bruno D (2011) Fish diseases and disorders, Vol 3: Viral, bacterial and fungal infections, 2nd edn. CAB International, Wallingford

WGMMUME (Working Group on Marine Mammal Unusual Mortality Events) (2006) Criteria for determining an unusual marine mammal mortality event. Fed Reg 71(240):75234-75236

Submitted: July 2, 2013; Accepted: January 20, 2013

Proofs received from author(s): March 31, 2014 